\title{
Role of P27 -P55 operon from Mycobacterium tuberculosis in the resistance to toxic compounds
}

\author{
María V Bianco', Federico C Blanco', Belén Imperiale², Marina A Forrellad ${ }^{1}$, Roxana V Rocha', Laura I Klepp', \\ Angel A Cataldi ${ }^{1}$, Nora Morcillo ${ }^{2}$ and Fabiana Bigi $i^{*}$
}

\begin{abstract}
Background: The P27-P55 (IprG-Rv1410c) operon is crucial for the survival of Mycobacterium tuberculosis, the causative agent of human tuberculosis, during infection in mice. P55 encodes an efflux pump that has been shown to provide Mycobacterium smegmatis and Mycobacterium bovis BCG with resistance to several drugs, while P27 encodes a mannosylated glycoprotein previously described as an antigen that modulates the immune response against mycobacteria. The objective of this study was to determine the individual contribution of the proteins encoded in the P27-P55 operon to the resistance to toxic compounds and to the cell wall integrity of $M$. tuberculosis.

Method: In order to test the susceptibility of a mutant of M. tuberculosis H37Rv in the P27-P55 operon to malachite green, sodium dodecyl sulfate, ethidium bromide, and first-line antituberculosis drugs, this strain together with the wild type strain and a set of complemented strains were cultivated in the presence and in the absence of these drugs. In addition, the malachite green decolorization rate of each strain was obtained from decolorization curves of malachite green in PBS containing bacterial suspensions.
\end{abstract}

Results: The mutant strain decolorized malachite green faster than the wild type strain and was hypersensitive to both malachite green and ethidium bromide, and more susceptible to the first-line antituberculosis drugs: isoniazid and ethambutol. The pump inhibitor reserpine reversed $M$. tuberculosis resistance to ethidium bromide. These results suggest that P27-P55 functions through an efflux-pump like mechanism. In addition, deletion of the P27-P55 operon made M. tuberculosis susceptible to sodium dodecyl sulfate, suggesting that the lack of both proteins causes alterations in the cell wall permeability of the bacterium. Importantly, both P27 and P55 are required to restore the wild type phenotypes in the mutant.

Conclusions: The results clearly indicate that P27 and P55 are functionally connected in processes that involve the preservation of the cell wall and the transport of toxic compounds away from the cells.

Keywords: Mycobacterium tuberculosis, IprG, P55, P27

\section{Background}

Infection by Mycobacterium tuberculosis is a major health problem worldwide [1]. Pathogenic mycobacterial species show remarkable ability to survive in the diverse conditions encountered during the infection process [2]. However, even after decades of investigation, the knowledge about the mycobacterial pathogenesis remains insufficient. The identification of the genes associated with the multiplication and survival of bacilli in the host

\footnotetext{
* Correspondence: fbigi@cnia.inta.gov.ar

'Instituto de Biotecnología, CICVyA-INTA, N. Repetto and De los Reseros,

1686 Hurlingham, Buenos Aires, Argentina

Full list of author information is available at the end of the article
}

has provided a framework to study $M$. tuberculosis virulence [3]. However, little is still known about the role of the encoded products in the interaction between the host and the pathogen. Elucidating these functions is then the next main challenge in tuberculosis research.

We have previously demonstrated that P27-P55 (lprG$R v 1410 c$ ) operon [4] is crucial for the survival of M. tuberculosis during infection in mice [5]. P55 encodes for the efflux pump, which has been shown to provide resistance to several drugs, likely through a process coupled to oxidative balance within the cell [6]. Also, it has been demonstrated that over-expression of P55 from M. tuberculosis in M. smegmatis confers resistance to 
several compounds by an efflux pumping activity [7]. $P 27$, on the other hand, encodes a lipoprotein previously described as an antigen in the $M$. tuberculosis complex [8] and, as many other mycobacterial lipoproteins, P27 is a mannosylated glycoprotein [9].

Although several publications have characterized the proteins encoded in the P27-P55 operon [4-14], the mechanism by which this operon contributes to the virulence of $M$. tuberculosis is still unclear. The finding that P27 causes an adverse effect when used as a protein-based vaccine [15], together with the fact that this glycolipoprotein inhibits MHC-II Ag processing, suggests that P27 acts modulating the immune response against mycobacteria (as an evasion mechanism) in favour of bacterial persistence [16].

Increasing evidence indicates that mycobacterial lipoproteins are involved in cell wall integrity either maintaining cell wall permeability [17] or participating in cell wall synthesis with specific functions [18]. Recently, it has been shown that P27 acts in cooperation with P55 to transport ethidium bromide in M. smegmatis [10], indicating that P27 is necessary for P55-mediated transport across the cell membrane. Moreover, it has been recently proposed that in mycobacteria, P27 functions as a carrier of glycolipids during their trafficking and delivery to the mycobacterial cell wall [11].

In order to gain more insight into the function of the P27-P55 operon, in the present work, we studied the contribution of both P27 and P55 on the resistance to toxic compounds as well as on the cell wall integrity of M. tuberculosis.

\section{Methods}

\section{Bacterial strains and culture media}

All cloning steps were performed in Escherichia coli DH5a. E. coli was grown either in Luria-Bertani (LB) broth or on LB agar. Mycobacterium strains were grown in Middlebrook 7H9 medium supplemented with $0.05 \%$ Tween 80 , albumin $0.5 \%$, dextrose $0.4 \%$, and $0.5 \%$ glycerol, or Middlebrook 7H10 supplemented with albumin $0.5 \%$, dextrose $0.4 \%$, and $0.5 \%$ glycerol. When necessary, $50 \mu \mathrm{g} / \mathrm{ml}$ hygromycin, $20 \mu \mathrm{g} / \mathrm{ml}$ kanamycin or $20 \mu \mathrm{g} / \mathrm{ml}$ reserpine were added to the media. Electrocompetent cells of the previously obtained $M$. tuberculosis $\Delta \mathrm{P} 27$ (Mt $\Delta$ P27) mutant [5] were prepared following the procedure described in [5]. For culture supernatant protein preparations, strains were cultured in Sauton supplemented with $0.5 \%$ glycerol.

\section{Construction of $\triangle \mathrm{P} 27 \mathrm{M}$. tuberculosis complemented strains}

Complemented strains of the Mt $\Delta \mathrm{P} 27$ mutant [5] expressing either P27 or P55 were generated in this study. The P27 gene under the control of the P27-P55 operon promoter was cloned into the pNBV1 vector [19]. pNBV1 was also used as a backbone vector to clone the $P 55$ gene under the $h s p 60$ promoter. These plasmids together with plasmid $\triangle \mathrm{P} 27 \mathrm{C}$, which express the P27-P55 operon under its own promoter in the pNBV1 backbone [5], were used to transform Mt $\Delta \mathrm{P} 27$ by electroporation [5]. The resulting complemented strains are referred to as Mt $\Delta \mathrm{P} 27:: \mathrm{P} 27, \mathrm{Mt} \Delta \mathrm{P} 27:: \mathrm{P} 55$ and $\mathrm{Mt} \Delta \mathrm{P} 27:: \mathrm{P} 27-\mathrm{P} 55$, respectively.

\section{Ethidium bromide sensitivity assays}

M. tuberculosis strains were grown in liquid medium in the presence of either $1 \mu \mathrm{g} / \mathrm{ml}$ or $0.5 \mu \mathrm{g} / \mathrm{ml}$ of ethidium bromide. When necessary, $20 \mu \mathrm{g} / \mathrm{ml}$ reserpine was added into de cultures. Bacterial growth was monitored by optical density (OD) and compared to growth in the absence of ethidium bromide.

\section{Malachite green decolorization assay}

The malachite decolorization assay was performed as described in Banaei et al. [17]. Briefly, malachite green (final concentration of $0.1 \mathrm{mg} /$ liter) was added to $4 \mathrm{ml}$ of mid-log bacterial cultures resuspended in phosphate-buffered saline (PBS) to an OD of 0.5 at $600 \mathrm{~nm}$. When necessary, $20 \mu \mathrm{g} / \mathrm{ml}$ reserpine was added into de cultures. Bacterial suspensions were immediately centrifuged and the absorbance at $620 \mathrm{~nm}$ was measured in the supernatants at 10-min intervals. Because of the photooxidation of malachite green, tubes were covered with foil and the experiments were performed under reduced light. The experiment was repeated three times. The decolorization rates were expressed as nanograms of dye decolorized every $10 \mathrm{~min}$ per $\mathrm{ml}$ of culture.

\section{Malachite green and SDS sensitivity assays}

Two methods were used to determine the susceptibilities of the M. tuberculosis strains to sodium dodecyl sulfate (SDS). Firstly, a disc assay was used to determine the inhibition of growth in the presence of SDS. Briefly, bacterial suspensions containing $10^{7}$ cells were spread on Middlebrook $7 \mathrm{H} 10$ agar plates, and discs containing $10 \mu \mathrm{l}$ of $10 \%$ SDS were placed in the middle of the plate. Halos were recorded after two weeks at $37^{\circ} \mathrm{C}$.

Secondly, the method described by Banaei et al. [17] was used to determine the loss of bacterial viability in the presence of a high concentration of SDS. Briefly, bacterial cultures grown to mid-log phase were diluted with growth medium to an OD of 0.05 at a wavelength of $600 \mathrm{~nm}$ and incubated with SDS $0.05 \%$ in duplicate. At 1 and $4 \mathrm{~h}$, bacterial CFU were counted on Middlebrook $7 \mathrm{H} 10$ agar plates.

The malachite green sensitivity assay was performed as follows: bacterial suspensions with $10^{6}$ cells were plated on Middlebrook 7H10 agar with or without $1 \mathrm{mg} /$ liter of 
malachite green. Plates were incubated at $37^{\circ} \mathrm{C}$ in the dark and CFUs were counted after 21 days in plates without malachite green and after 40 days in plates containing malachite green.

\section{Protein preparations, SDS-PAGE and Western blots}

Subcellular fractions of Mycobacterium strains were obtained as previously described [8]. Proteins were separated in SDS-PAGE and transferred to nitrocellulose filters. Western blot assays were performed as previously described [8] with the antibody anti-P27 Mab antibody (1:500). Alkaline phosphatase-conjugated anti-mouse immunoglobulin G (1:10000/Sigma-Aldrich) was used as secondary antibody.

First-line drug susceptibility testing (DST) by the colorimetric microplate-based method

To determine the minimal inhibitory concentration (MIC) of anti-tuberculosis drugs, a non commercial, microplate colorimetric-based method with resazurin (REMA) was used as a general indicator of cellular growth and viability, following a previously described method [20-22]. Briefly, a 96 wells, microtiter, flat bottom plate was used to perform DST to isoniazid, rifampicin and ethambutol. When necessary, $20 \mu \mathrm{g} / \mathrm{ml}$ reserpine was added into de cultures. Serial twofold dilutions of the drugs were performed and wells were left free of drugs to be used as growth controls. Wells were inoculated with $100 \mu \mathrm{l}$ of 1:25 from a bacterial suspension with turbidity comparable to 1.0 MacFarland standard (original bacterial suspension). Plates were incubated for 5 days at $37^{\circ} \mathrm{C}$ at normal atmosphere. After the incubation period, $0.02 \%$ of resazurin was added to the wells and incubated for $24 \mathrm{~h}$. The MIC for each particular drug was considered as the lowest concentration showing less change of colour than the growth controls.

\section{Statistical analysis}

The data were analyzed with Microsoft Excel statistical software using Student $t$ test. $p$ values $<0.05$ were considered statistically significant.

\section{Results}

P27 localizes in the cell wall, cell membrane and culture supernatant

Previously, we have shown that P27 localizes in the cell membrane of Mycobacterium bovis [8]. However, in a recent study, P27 was purified from culture supernatant of $M$. tuberculosis by binding to concanavalin A [9], indicating that P27 is secreted outside the bacterium. In order to confirm these previous findings we carried out a cellular localization study of P27. For this purpose, the localization of P27 was assessed in H37Rv as well as in the mutant Mt $\Delta \mathrm{P} 27$, and in a set of complemented strains. Mt $\triangle \mathrm{P} 27$ is a strain knockout in the P27-P55 operon generated by the insertion of the kanamycin resistance cassette into the $P 27$ gene of $M$. tuberculosis H37Rv [5]. Protein fractions were obtained from Mt $\triangle \mathrm{P} 27$, the complemented strains carrying a wild type copy of either P27 or P55, a full complemented strain transformed with the complete operon and the wild type strain. Western blotting using an anti-LprG antibody showed a $27-\mathrm{kDa}$ band present in the cell wall, cell membrane and culture supernatant but absent in the cytoplasm fraction of the wild type and complemented strains, Mt $\Delta \mathrm{P} 27:: \mathrm{P} 27$ and Mt $\Delta \mathrm{P} 27:: \mathrm{P} 27-\mathrm{P} 55$. Therefore, the expression of $\mathrm{P} 27$ in both Mt $\Delta \mathrm{P} 27:: \mathrm{P} 27$ and Mt $\Delta$ P27::P27-P55 strains confirms the functionality and integrity of the plasmids used to complement the mutant strain (Figure 1). No band was detected in any of the protein fractions of the Mt $\Delta \mathrm{P} 27$ mutant and Mt $\Delta \mathrm{P} 27:: \mathrm{P} 55$ complemented strain (Figure 1). These results indicate that P27 is secreted from the bacterium to the medium but also demonstrate that this protein is a component of the cell wall of $M$. tuberculosis. Expression of P55 in the wild type and complemented strains was confirmed by RT-qPCR (see additional file 1).

\section{Sensitivity of $\triangle \mathrm{P} 27$ mutant to malachite green}

It has been demonstrated that in the absence of the lipoprotein LspA, M. tuberculosis is more sensitive to

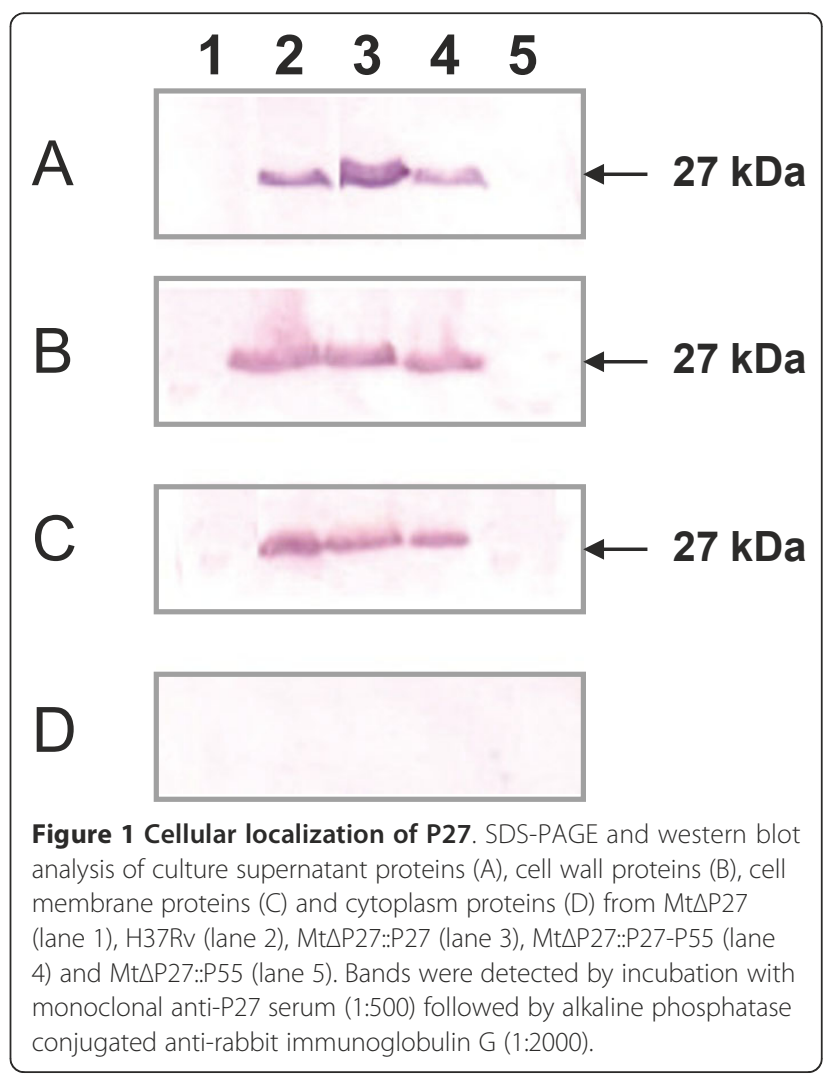


malachite green, likely due to a cell wall permeability defect [17]. Thus, we decided to assess the contribution of both P27 and P55 to the resistance of M. tuberculosis to malachite green. For this purpose, equivalent densities of the wild type, the mutant and complemented strains were plated in media with and without malachite green. In the presence of malachite green, the Mt $\Delta \mathrm{P} 27$ mutant showed $100 \%$ of reduction on CFU counts while the wild type and the full complemented strains exhibited $45.2 \%$ and $62.5 \%$ of inhibition, respectively, as compared to the growth in the absence of malachite green. Complementation of the Mt $\triangle \mathrm{P} 27$ mutant with P27 or $P 55$ alone reduced the level of inhibition to $90.2 \%$ and $81.9 \%$, respectively (Figure 2 ). These results indicate that both P27 and P55 are essential for M. tuberculosis to resist to the toxic effect exerted by malachite green and that the only presence of P55 allows partial levels of resistance.

In order to gain insights into the mechanism involved in the resistance to malachite green we compared the ability of the Mt $\Delta$ P27 mutant to decolorize malachite green with those of the complemented and wild type strains. Table 1 (and additional file 2) shows that the Mt $\Delta$ P27 mutant decolorized malachite green at a rate greater than that of the wild-type strain. Importantly, the expression of either P27 or P55 in the mutant did not complement the wild type phenotype. The decolorization rate of the mutant strain complemented with both P27 and P55 was equivalent to that of the wild type strain, indicating that only the reintroduction of the complete operon restored the wild type phenotype of $M$. tuberculosis. To elucidate whether an efflux pump activity was the mechanism by which P27 and, more likely, P55 excluded malachite green from the bacteria, the decolorization rates were determined in cultures of $M$. tuberculosis and the complemented strains in the presence of reserpine, a multidrug resistance pump inhibitor. Unexpectedly, in the presence of subinhibitory concentration of reserpine, the decolorization rates of malachite green for all strains were equivalent and comparable to those of the wild type and full complemented strain, in the absence of reserpine. This result suggests that reserpine acts somehow inhibiting the mechanism that mediates the decolorization of malachite green by $M$. tuberculosis. In agreement with this presumption, it has been suggested that Mycobacterium avium decolorizes malachite green through a process that involves a membrane protein, likely cytochrome $\mathrm{P}-450$, and that this process requires hydrogen ion transfer across the membrane [23]. However, whether or not reserpine can inhibit decolorization activity needs to be investigated.

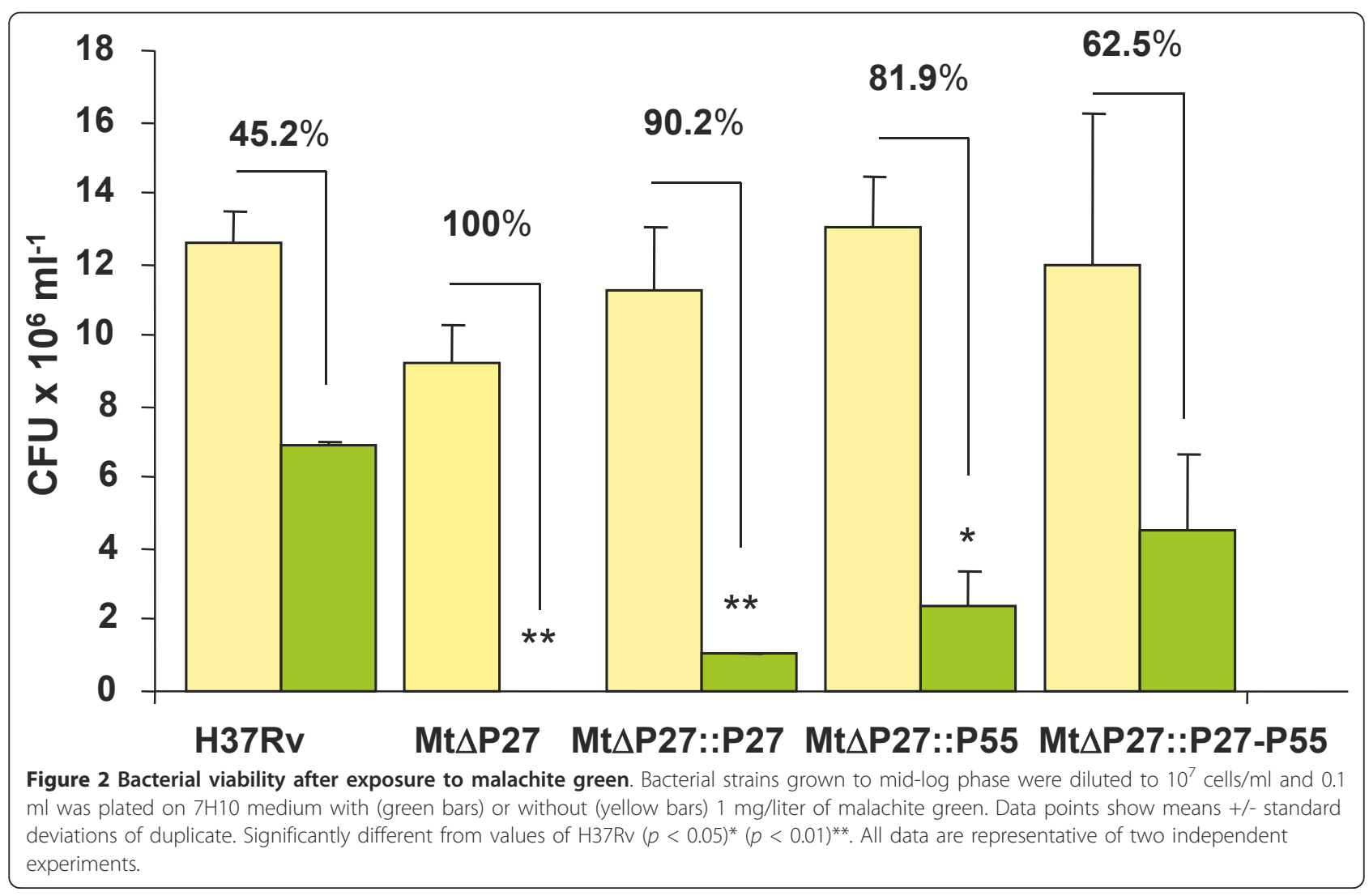


Table 1 Rates of malachite green decolorization by M.tuberculosis $\triangle$ P27 strains

\begin{tabular}{|c|c|c|}
\hline \multirow[b]{3}{*}{ Strains } & \multicolumn{2}{|c|}{$\begin{array}{c}\text { Decolorization rate } \text { r }^{\S} /- \text { SD } \\
\text { Reserpine } 20 \mu \mathrm{g} / \mathrm{ml}\end{array}$} \\
\hline & - & + \\
\hline & & \\
\hline MtH37Rv & $9.0(0.01)$ & $10.7(0.74)$ \\
\hline $\mathrm{Mt} \triangle \mathrm{P} 27$ & $15.3(0.54)^{*}$ & $11.6(0.34)$ \\
\hline $\mathrm{Mt} \triangle \mathrm{P} 27+\mathrm{P} 27$ & $15.3(0.54)^{*}$ & $12.3(1.90)$ \\
\hline $\mathrm{M} t \triangle \mathrm{P} 27+\mathrm{P} 55$ & $13.1(0.28)^{*}$ & $13.3(1.82)$ \\
\hline $\mathrm{M} t \triangle \mathrm{P} 27+\mathrm{P} 27+\mathrm{P} 55$ & $9.5(0.24)$ & $11.9(1.60)$ \\
\hline
\end{tabular}

${ }_{5}^{\text {Rates are expressed as nanograms of malachite green decolorized in } 10 \mathrm{~min}}$ per milliliter of culture at $37^{\circ} \mathrm{C}$. Values show means $+/$ - standard deviations of duplicates. All data are representative of three independent experiments.

*Significantly different from values of H37Rv $(p<0.005)$.

The lack of P27 and P55 alters the cell wall permeability of $M$. tuberculosis

Drage and collaborators [11] have demonstrated that P27 binds glycolipids, which are central components of the mycobacterial cell wall. This suggests a role of the P27-P55 operon in the cell wall integrity of M. tuberculosis. To test this hypothesis, we assessed the impact of a mutation in the P27-P55 operon on the cell permeability of $M$. tuberculosis. To this end, we determined the susceptibility of the Mt $\Delta \mathrm{P} 27$ to the detergent SDS. In the presence of SDS, the growth of the mutant strain was inhibited to a larger extent than that of the wild type (Table 2). The reintroduction of a wild type copy of the operon in the mutant strain partially restored the resistance of $M$. tuberculosis to SDS. Treatment of Mt $\triangle \mathrm{P} 27$ with $0.05 \%$ SDS for 1 and $4 \mathrm{~h}$ resulted in $55 \%$ and $75 \%$ loss of viability, respectively (Figure 3 ). After 1 h of SDS treatment, the expression of either P55 or P27 partially restored ( $32 \%$ and $25 \%$ loss of viability) the wild type level of resistance to SDS in the mutant strain. The wild type and the double complemented strain were unaffected at $1 \mathrm{~h}$ and fairly affected at $4 \mathrm{~h}$ post treatment. Taken together these results demonstrate that the inactivation of the P27-P55 operon alters the sensitivity of $M$. tuberculosis to SDS, indicating that both proteins are required to maintain the integrity of the cell wall.

\section{Sensitivity to isoniazid, ethambutol and ethidium} bromide is increased in the $\Delta \mathrm{P} 27$ mutant

To explore the possibility that the absence of P27 and P55 increases the susceptibility of $M$. tuberculosis to cell wall-targeting drugs, we tested the resistance of Mt $\Delta \mathrm{P} 27$ to rifampicin, ethambutol and isoniazid. While the lack of P27 and P55 did not show to affect the resistance to rifampicin, mutant Mt $\Delta \mathrm{P} 27$ was more susceptible to both isoniazid and ethambutol than the wild type strain. The wild type level of resistance to isoniazid and
Table 2 Susceptibility of M.tuberculosis $\Delta \mathrm{P} 27$ strains to SDS

\begin{tabular}{lc}
\hline Strain & Inhibition zone $(\mathbf{c m})^{\S}$ \\
\hline H37Rv & $2.43(0.287)$ \\
Mt $\triangle$ P27 & $3.75(0.354) *$ \\
Mt $\triangle$ P27+P27 & $3.44(0.134) *$ \\
Mt $\triangle$ P27+P55 & $3.05(0.071)^{*}$ \\
Mt $\triangle$ P27+P27+P55 & $2.71(0.103)$ \\
\hline
\end{tabular}

${ }^{5}$ Values show means +/- standard deviations of duplicates. All data are representative of three independent experiments. *Significantly different from values of H37Rv $(p<0.05)$.

ethambutol was reversed when a copy of the whole operon was introduced in the mutant strain. However, the introduction of P27 or P55 alone did not complement the wild type level of resistance (Table 3 ), indicating that both genes are implicated in this mechanism. The addition of subinhibitory concentration of reserpine did not significantly affect the susceptibility of the wild type and full complemented strain to isoniazid and ethambutol (data not shown), which is consistent with previous reports $[24,25]$.

Because it has been demonstrated that a mutant of Mycobacterium smegmatis in the homologous P27-P55 operon is more susceptible to ethidium bromide, and that drug resistance is restored by the intact operon from $M$. tuberculosis [10], we decided to investigate whether the P27-P55 operon provides M. tuberculosis resistance to ethidium bromide. Mt $\Delta \mathrm{P} 27$ showed much higher sensitivity to both high and low concentrations of ethidium bromide than the wild type strain (Figure 4 ). Introduction of a wild type allele of the operon restored the ethidium bromide resistance to levels equivalent to those of the wild type strain. While complementation with P27 did not significantly modify the susceptibility of Mt $\Delta \mathrm{P} 27$ to ethidium bromide, the introduction of P55 provided the mutant with partial resistance to low concentration of the drug. In the presence of reserpine, all strains were sensitive to ethidium bromide (Figure 4)

\section{Discussion}

The increased sensitivity to membrane-perturbing compounds, such as SDS, observed in the mutant Mt $\Delta$ P27 is in agreement with a recent report demonstrating that P27 has a role in $M$. tuberculosis cell wall integrity by binding to glycolipids [11]. Other lipoproteins have also been demonstrated to have function related with cell wall of mycobacteria. Such is the example of LppX, a lipoprotein required for the translocation of phthiocerol dimycocerosates (DIM) to the outer membrane of $M$. tuberculosis [18]. Here we found evidences suggesting that P55 is also required to maintain the cell wall impermeability of $M$. tuberculosis, which is consistent with its 


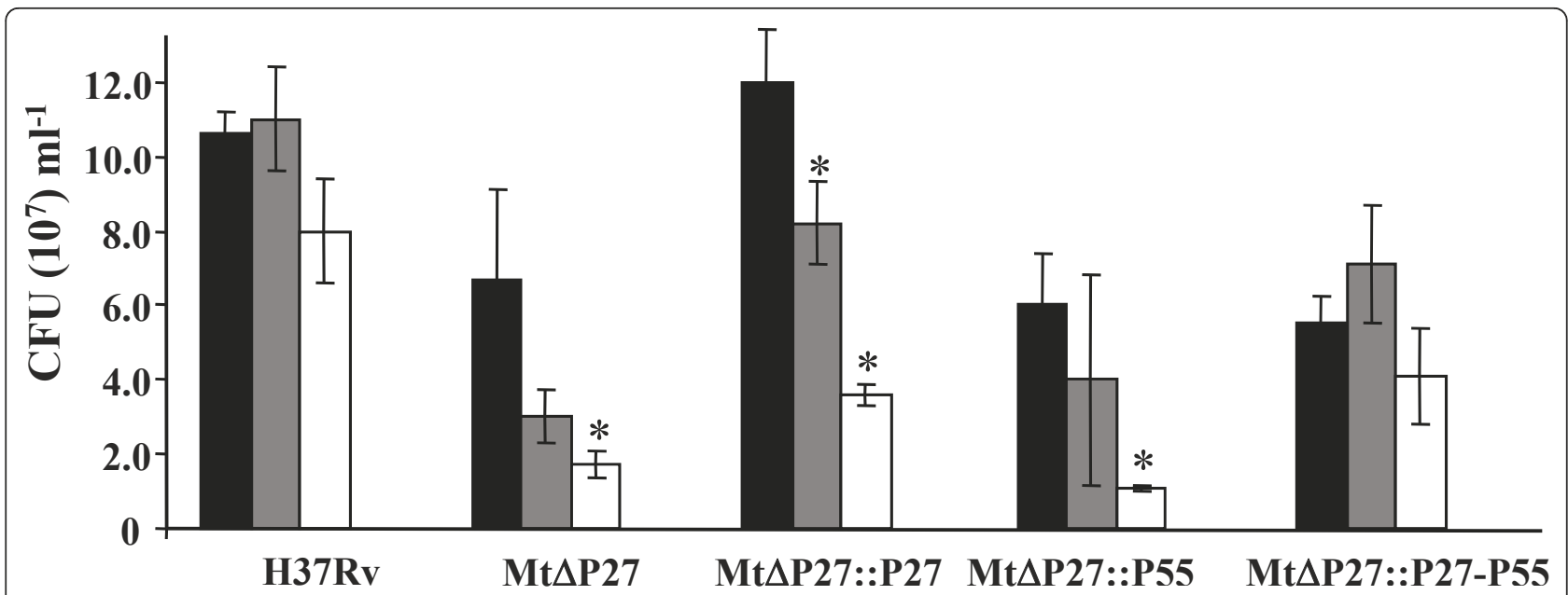

Figure 3 Bacterial viability after exposure to SDS. Bacterial strains grown to mid-log phase were diluted to an OD 600 nm of 0.05 in $7 \mathrm{H} 9$ medium containing $0.05 \%$ SDS and incubated at 37C for $0 \mathrm{~h}$ (black bars), $1 \mathrm{~h}$ (gray bars) and $4 \mathrm{~h}$ (white bars). Data points show means $+/$ standard deviations of duplicates. *Significantly different from values at T0 $(p<0.05)$. All data are representative of two independent experiments.

cell membrane localization [7]. Although we have previously demonstrated that P27 localizes in the cell membrane fraction of $M$. bovis [8] here we showed that P27 is secreted to the culture supernatant of M. tuberculosis. However, a considerable amount of the protein was also detected in the mycobacterial cell wall, which is consistent with the proposed role of P27 in the transport of glycolipids such as lipomannans and lipoarabinomannans [11]. Therefore, the localization of P27 in both culture supernatant and cell wall fractions suggests that the alteration of the cell wall integrity detected in the mutant may be due not only to the mislocalization of P27 in the cell wall but also to the lack of some specific function exerted by the secreted P27. Regarding to this last aspect, the structure of P27 from M. tuberculosis has been very recently defined and a role of P27 in the binding to mycobacterial glycolipids that are TLR2 agonists has been proposed [11]. In agreement with the hypothesis that lipoproteins participate in the cell wall integrity, Banaei et al [17] found that the lack of LspA expression in $M$. tuberculosis causes higher susceptibility to malachite green and higher decolorization of this compound in the presence of the bacterium. These authors proposed that defects in cell wall permeability are responsible for the hypersensitivity of the $l s p A$ mutant to malachite green. We found that in the absence of P27-P55 expression, M. tuberculosis is extremely sensitive to malachite green and that the mutant decolorized malachite green faster than the wild type. The expression of P55 alone, but not of P27, in the mutant strain partially restored the wild type level of resistance to malachite green, supporting the idea that P55, through an efflux system is mainly involved in this phenomenon. Unfortunately, the addition of reserpine to strain cultures blocked the decolorization process, thus not allowing us to assess the effect of this drug in the efflux pump activity encoded in the P27-P55 operon.

The higher susceptibility to isoniazid and ethambutol of the Mt $\Delta$ P27 mutant is in agreement with a previous publication in which an increased expression of P55 was detected in the presence of isoniazid in a multidrug-resistant M. tuberculosis strain [26]. Moreover, the involvement of P55 in the mechanism of antibiotic resistance has been demonstrated in Mycobacterium bovis BCG [6]. Based on these results, which demonstrate that a P55knockout $M$. bovis BCG strain is more susceptible to rifampicin, ethambutol and other drugs, Ramón-García et al. proposed that P55 plays an essential role of the efflux pump in detoxification processes coupled to oxidative balance within the bacterium. Consistently with that,

Table 3 Antimicrobial susceptibilities of M.tuberculosis $\Delta$ P27 strains

\begin{tabular}{|c|c|c|c|c|c|}
\hline \multicolumn{6}{|c|}{ MIC (mg/liter) for M. tuberculosis strain* } \\
\hline & MtH37Rv & Mt $\Delta \mathrm{P} 27$ & $\mathrm{Mt} \Delta \mathrm{P} 27+\mathrm{P} 27$ & $\mathrm{Mt} \Delta \mathrm{P} 27+\mathrm{P} 55$ & $\mathrm{Mt} \Delta \mathrm{P} 27+\mathrm{P} 27+\mathrm{P} 55$ \\
\hline Rifampicin & 0.06 & 0.06 & 0.06 & 0.06 & 0.06 \\
\hline Isoniazid & 0.06 & 0.03 & 0.03 & 0.03 & 0.06 \\
\hline Ethambutol & 2 & 1 & 1 & 1 & 2 \\
\hline
\end{tabular}

${ }^{*}$ MICs were determined by the colorimetric microplate-based method. 


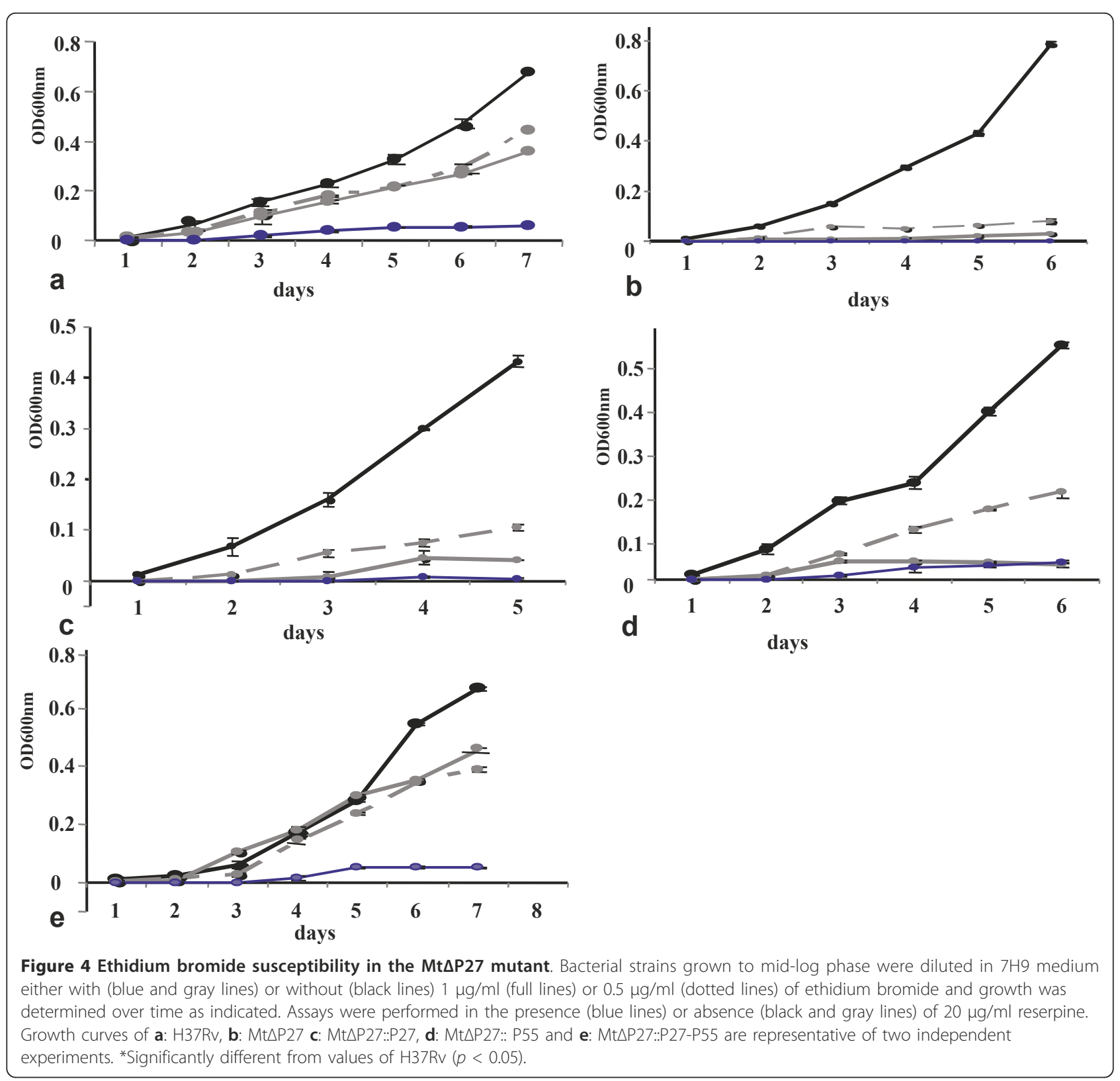

here we found that both P27 and P55 provide M. tuberculosis with resistance to ethambutol; however, the susceptibility of $M$. tuberculosis to rifampicin was unchanged in the Mt $\Delta \mathrm{P} 27$ mutant, suggesting that the intrinsic mechanism of antibiotic resistance is determined by the genetic background of the bacterial species.

The high susceptibility of Mt $\Delta \mathrm{P} 27$ to ethidium bromide also supports a role of P27 and P55 in efflux transport. Farrow and Rubin have demonstrated that P55 mediates the transport of ethidium bromide outside $M$. smegmatis and that P27 is required for this process [10]. The finding that reserpine alters the intrinsic resistance of M. smegmatis [10] and M. tuberculosis (this study) to ethidium bromide indicates that the susceptibility observed in the Mt $\Delta \mathrm{P} 27$ mutant is due to the lack of the efflux pump function rather than to an increase in cell wall permeability. This assumption is supported by the fact that the introduction of P55 into the Mt $\Delta \mathrm{P} 27$ mutant showed partial resistance to ethidium bromide.

\section{Conclusions}

Our results showed here demonstrate that P27 and P55 are functionally connected in processes associated with cell wall function by contributing to both the impermeability of the cell wall and the transport of toxic compounds away from the cells. In this regard, it has been 
proposed that P55 plays a role in the detoxification systems linked to respiratory processes and maintenance of the redox balance within the cell [6]. Ongoing research is aimed to find out the precise role of P27 in these processes.

We propose that the requirement of P27 and P55 for the replication and persistence of the bacterium during the host infection is based on two aspects: the physiological role of P27 and P55 in cell wall function and transport, which are relevant during the in vivo growth of M. tuberculosis, and the antigenic properties of P27 to exert immune evasion during persistent $M$. tuberculosis infection.

\section{Additional material}

\section{Additional file 1: Transcription of P55 in $\triangle \mathrm{P} 27$ complemented}

strains. DNA-free RNA extracted from middle logarithmic-phase cultures of H37Rv, Mt $\triangle P 27:: P 55$ and Mt $\triangle P 27:$ P27-P55 was reverse transcribed using random hexamers as primers. Total CDNA samples were used as template in Q-PCR assays to relatively quantify the number of copies of P55 mRNA. Results were presented as relative expression to H37Rv.

Additional file 2: Decolorization of malachite green in Mt $\triangle \mathrm{P} 27$ mutant. Bacterial strains grown to mid-log phase were diluted to an $O D$ $600 \mathrm{~nm}$ of $0.40-0.44$ in PBS. Bacterial suspensions were centrifuged the absorbance at OD $620 \mathrm{~nm}$ was measured in the supernatant at time points indicated. *Significantly different from values of the wild type strain.

\section{Acknowledgements}

The present study was supported by NIH 1R01Al083084-01, SECyT grant PICT2324 and INTA grant AEBIO243512. FB and AAC are CONICET fellows. We thank Luis Fernandez for the bibliography provided. We also thank Dr. Belisle (Colorado State University) for providing us with the monoclonal antiLprG antibody.

\section{Author details}

'Instituto de Biotecnología, CICVyA-INTA, N. Repetto and De los Reseros, 1686 Hurlingham, Buenos Aires, Argentina. ${ }^{2}$ Reference Laboratory of Tuberculosis Control Program of Buenos Aires Province, Dr Cetrángolo Hospital, Buenos Aires, Argentina.

\section{Authors' contributions}

MVB performed the decolorization assays as well as the SDS and ethidium bromide susceptibility assays. RVR generated the complemented strains. FCB and MAF performed the RT-qPCRs. BI and NM carried out the first-line drug susceptibility testing. AAC and LIK participated in the design of the study. FB conceived the study, participated in its design and coordination, and drafted the manuscript. All authors read and approved the final manuscript.

\section{Competing interests}

The authors declare that they have no competing interests.

Received: 21 September 2010 Accepted: 16 July 2011 Published: 16 July 2011

\section{References}

1. The Current Status of TB in the World. In The Art \& Science of Tuberculosis Vaccine Development. Volume Chapter 2.. 2 edition. Edited by: Mohd Nor N, Acosta A, Sarmiento ME. Selangor Darul Ehsan: Oxford Fajar Sdn. Bhd; 2011:18-29.

2. Kirschner DE, Young D, Flynn JL: Tuberculosis: global approaches to a global disease. Curr Opin Biotechnol 2010, 21:524-523.
3. Smith I: Mycobacterium tuberculosis pathogenesis and molecular determinants of virulence. Clin Microbiol Rev 2003, 16:463-496.

4. Bigi F, Alito A, Romano MI, Zumarraga M, Caimi K, Cataldi A: The gene encoding P27 lipoprotein and a putative antibiotic-resistance gene form an operon in Mycobacterium tuberculosis and Mycobacterium bovis . Microbiology 2000, 146:1011-1018.

5. Bigi F, Gioffré A, Klepp L, Santangelo MP, Alito A, Caimi K, Meikle V, Zumárraga M, Taboga O, Romano Ml, Cataldi A: The knockout of the IprGRv1410 operon produces strong attenuation of Mycobacterium tuberculosis. Microbes Infect 2004, 6:182-187.

6. Ramón-García S, Martín C, Thompson CJ, Ainsa JA: Role of the Mycobacterium tuberculosis P55 efflux pump in intrinsic drug resistance, oxidative stress responses, and growth. Antimicrob Agents Chemother 2009, 53:3675-3682.

7. Silva PE, Bigi F, Santangelo MP, Romano MI, Martín C, Cataldi A, Aínsa JA: Characterization of P55, a multidrug efflux pump in Mycobacterium bovis and Mycobacterium tuberculosis. Antimicrob Agents Chemother 2001, 45:800-804.

8. Bigi F, Espitia C, Alito A, Zumarraga M, Romano Ml, Cravero S, Cataldi A: A novel $27 \mathrm{kDa}$ lipoprotein antigen from Mycobacterium bovis. Microbiology 1997, 143:3599-35605.

9. González-Zamorano M, Mendoza-Hernández G, Xolalpa W, Parada C, Vallecillo AJ, Bigi F, Espitia C: Mycobacterium tuberculosis glycoproteomics based on ConA-lectin affinity capture of mannosylated proteins. J Proteome Res 2009, 8:721-733.

10. Farrow MF, Rubin EJ: Function of a mycobacterial major facilitator superfamily pump requires a membrane-associated lipoprotein. $J$ Bacteriol 2008, 190:1783-1791.

11. Drage MG, Tsai HC, Pecora ND, Cheng TY, Arida AR, Shukla S, Rojas RE, Seshadri C, Moody DB, Boom WH, Sacchettini JC, Harding CV: Mycobacterium tuberculosis lipoprotein LprG (Rv1411c) binds triacylated glycolipid agonists of Toll-like receptor 2. Nat Struct Mol Biol 2010, 17:1088-1095.

12. Gehring AJ, Dobos KM, Belisle JT, Harding CV, Boom WH: Mycobacterium tuberculosis LprG (Rv1411c): a novel TLR-2 ligand that inhibits human macrophage class II MHC antigen processing. J Immunol 2004, 15:2660-2668.

13. Drage MG, Pecora ND, Hise AG, Febbraio M, Silverstein RL, Golenbock DT, Boom WH, Harding CV: TLR2 and its co-receptors determine responses of macrophages and dendritic cells to lipoproteins of Mycobacterium tuberculosis. Cell Immunol 2009, 258:29-37.

14. Carroll MV, Sim RB, Bigi F, Jäkel A, Antrobus R, Mitchell DA: Identification of four novel DC-SIGN ligands on Mycobacterium bovis BCG. Protein Cell 2010, 1:859-870.

15. Hovav AH, Mullerad J, Davidovitch L, Fishman Y, Bigi F, Cataldi A, Bercovier H: The Mycobacterium tuberculosis recombinant 27-kilodalton lipoprotein induces a strong Th1-type immune response deleterious to protection. Infect Immun 2003, 71:3146-3154.

16. Sieling PA, Hill PJ, Dobos KM, Brookman K, Kuhlman AM, Fabri M, Krutzik SR, Rea TH, Heaslip DG, Belisle JT, Modlin RL: Conserved mycobacterial lipoglycoproteins activate TLR2 but also require glycosylation for MHC class II-restricted T cell activation. J Immunol 2008, 180:5833-5842.

17. Banaei $N$, Kincaid EZ, Lin SY, Desmond E, Jacobs WR Jr, Ernst JD: Lipoprotein processing is essential for resistance of Mycobacterium tuberculosis to malachite green. Antimicrob Agents Chemother 2009, 53:3799-37802.

18. Sulzenbacher G, Canaan S, Bordat Y, Neyrolles O, Stadthagen G, RoigZamboni V, Rauzier J, Maurin D, Laval F, Daffé M, Cambillau C, Gicquel B, Bourne $Y$, Jackson M: LppX is a lipoprotein required for the translocation of phthiocerol dimycocerosates to the surface of Mycobacterium tuberculosis. EMBO J 2006, 25:1436-1444.

19. Howard NS, Gomez JE, Ko C, Bishai WR: Colour selection with a hygromycin-resistance-based Escherichia coli-mycobacterial shuttle vector. Gene 1995, 166:181-182.

20. Martin A, Morcillo N, Lemus D, Montoro E, Telles MA, Simboli N, Pontino M, Porras T, León C, Velasco M, Chacon L, Barrera L, Ritacco V, Portaels F, Palomino JC: Multicenter study of MTT and resazurin assays for testing susceptibility to first-line anti-tuberculosis drugs. Int I Tuberc Lung Dis 2005, 9:901-906.

21. Pontino MV, Di Giulio B, Fernandez C, Imperiale B, Bodon A, Morcillo N: Evaluation of a colorimetric micromethod for determining the minimal 
inhibitory concentration of antibiotics against Mycobacterium tuberculosis. Rev Arg Microbiol 2006, 38:145-151.

22. Morcillo N, Imperiale B, Di Giulio B: Evaluation of MGI 960 and the colorimetric-based method for tuberculosis drug susceptibility testing. Int J Tuberc Lung Dis 2010, 14:1169-1175.

23. Jones JJ, Falkinham JO: Decolorization of malachite green and crystal violet by waterborne pathogenic mycobacteria. Antimicrob Agents Chemother 2003, 47:2323-2326.

24. Piddock $\amalg$, Ricci V: Accumulation of KRM-1648 by Mycobacterium aurum and Mycobacterium tuberculosis. J Antimicrob Chemother 2000, 45:681-684.

25. Colangeli R, Helb D, Sridharan S, Sun J, Varma-Basil M, Hazbón MH,

Harbacheuski R, Megjugorac NJ, Jacobs WR Jr, Holzenburg A, Sacchettini JC, Alland D: The Mycobacterium tuberculosis iniA gene is essential for activity of an efflux pump that confers drug tolerance to both isoniazid and ethambutol. Mol Microbiol 2005, 55:1829-1840.

26. Jiang X, Zhang W, Zhang Y, Gao F, Lu C, Zhang X, Wang H: Assessment of efflux pump gene expression in a clinical isolate Mycobacterium tuberculosis by real-time reverse transcription PCR. Microb Drug Resist 2008, 14:7-11.

\section{Pre-publication history}

The pre-publication history for this paper can be accessed here:

http://www.biomedcentral.com/1471-2334/11/195/prepub

doi:10.1186/1471-2334-11-195

Cite this article as: Bianco et al:: Role of P27 -P55 operon from

Mycobacterium tuberculosis in the resistance to toxic compounds. BMC Infectious Diseases 2011 11:195.

\section{Submit your next manuscript to BioMed Central} and take full advantage of:

- Convenient online submission

- Thorough peer review

- No space constraints or color figure charges

- Immediate publication on acceptance

- Inclusion in PubMed, CAS, Scopus and Google Scholar

- Research which is freely available for redistribution

Submit your manuscript at www.biomedcentral.com/submit 